\title{
The clinical features of the overlap between COPD and asthma
}

\author{
Megan Hardin ${ }^{1,2^{*}}$, Edwin K Silverman ${ }^{1,2}$, R Graham Barr ${ }^{3}$, Nadia N Hansel ${ }^{4}$, Joyce D Schroeder ${ }^{5}$, Barry J Make ${ }^{5}$, \\ James D Crapo ${ }^{5}$ and Craig P Hersh ${ }^{1,2}$, for the COPDGene Investigators
}

\begin{abstract}
Background: The coexistence of COPD and asthma is widely recognized but has not been well described. This study characterizes clinical features, spirometry, and chest CT scans of smoking subjects with both COPD and asthma.

Methods: We performed a cross-sectional study comparing subjects with COPD and asthma to subjects with COPD alone in the COPDGene Study.

Results: 119 (13\%) of 915 subjects with COPD reported a history of physician-diagnosed asthma. These subjects were younger (61.3 vs 64.7 years old, $p=0.0001$ ) with lower lifetime smoking intensity (43.7 vs 55.1 pack years, $p=$ 0.0001). More African-Americans reported a history of asthma (33.6\% vs $15.6 \%, \mathrm{p}<0.0001)$. Subjects with COPD and asthma demonstrated worse disease-related quality of life, were more likely to have had a severe COPD exacerbation in the past year, and were more likely to experience frequent exacerbations (OR 3.55 [2.19, 5.75], p < 0.0001). Subjects with COPD and asthma demonstrated greater gas-trapping on chest $C T$. There were no differences in spirometry or CT measurements of emphysema or airway wall thickness.

Conclusion: Subjects with COPD and asthma represent a relevant clinical population, with worse health-related quality of life. They experience more frequent and severe respiratory exacerbations despite younger age and reduced lifetime smoking history.
\end{abstract}

Trial registration: ClinicalTrials.gov: NCT00608764

Keywords: Airway hyperresponsiveness, asthma, Chronic obstructive pulmonary disease, emphysema, Exacerbation, Gas-trapping

\section{Background}

Chronic Obstructive Pulmonary Disease (COPD) affects over 10 million Americans. In the United States, COPD is the third leading cause of death [1] and is responsible for over $\$ 15$ billion in annual healthcare costs [2]. World-wide, COPD is one of the few conditions in which mortality is rising, and it is estimated to become the third leading cause of death by 2020[3,4]. More than $40 \%$ of patients with COPD will additionally report a history of asthma, and this dual-diagnosis increases with age $[5,6]$.

\footnotetext{
* Correspondence: megan.hardin@channing.harvard.edu

'Channing Laboratory, Brigham and Women's Hospital, Harvard Medical School, Boston, MA, USA

Full list of author information is available at the end of the article
}

There is increasing evidence that patients who have COPD and asthma experience more rapid disease progression than those with either disease alone. Airway hyperresponsiveness (AHR) and the diagnosis of asthma have been associated with greater decline in $\mathrm{FEV}_{1}$ in both smokers and nonsmokers [7-9] and asthma has been recognized as a risk factor for COPD [10]. The presence of AHR in patients with COPD has been associated with an increase in COPD exacerbations and overall mortality [11], and the coexistence of asthma and COPD is associated with increased co-morbidities and health-care utilization $[12,13]$.

Despite these known interactions between COPD and asthma, the clinical aspects of this overlap population have not been well described. In fact, the dual-diagnosis of COPD and asthma is often an exclusion criterion for 
participation in studies investigating either disease alone [14]. The aim of this study was to examine the clinical, physiologic and chest CT scan features of subjects with the overlapping diagnoses of COPD and asthma in comparison to subjects with COPD alone. We hypothesized that subjects with COPD and asthma would have markers of more severe disease, including greater exacerbation frequency and worse quality of life scores. We analyzed subjects in the Genetic Epidemiology of COPD Study (COPDGene) study, a large case-control study of COPD for which asthma was not an exclusion criterion.

\section{Methods}

\section{Study Subjects and Procedures}

We performed a cross-sectional observational study among smoking subjects to investigate unique clinical characteristics of subjects with COPD and asthma compared to subjects with COPD alone, using data complete through November 2010 from the first 2500 subjects enrolled in the COPDGene Study. COPDGene is a multicenter study that aims to improve classification of COPD phenotypes as well as determine the genetic background of this disease. Study details including enrollment procedures and phenotyping have been described [15] and all protocols and questionnaires are available at http://www.copdgene.org. Briefly, all subjects had at least a 10 pack-year smoking history and were self-identified non-Hispanic whites or non-Hispanic African Americans between 45-80 years old. Exclusion criteria included pregnancy, active cancer, and respiratory disorders other than asthma. 21 clinical centers participated in this study and IRB approval was obtained for all participating centers. All subjects signed informed consent prior to enrollment.

All study subjects completed standardized questionnaires regarding medical history and respiratory symptoms. Measures of disease severity included healthrelated quality of life as determined by the St George's Respiratory Questionnaire (SGRQ) [16], predicted mortality using the BODE index (Body mass index, airflow obstruction, dyspnea and exercise capacity index) [17], history of hay fever, respiratory medication use, and history of exacerbations of COPD. Severe exacerbations were defined as respiratory exacerbations in the year prior to enrollment that resulted in presentation to a hospital or emergency department. Frequent exacerbators were defined as those subjects who experienced 2 or more respiratory exacerbations that required antibiotics, steroids, or presentation to a physician or hospital in the year prior to enrollment. This definition was chosen based on recent data demonstrating that a history of two or more exacerbations in the prior year is a stable phenotype in COPD, which can predict future frequent exacerbations [18]. Number of exacerbations was defined as the absolute number of exacerbations each subject experienced in the year prior to enrollment. All subjects performed standardized pre-and post-bronchodilator spirometry (180 mcg [2 puffs] of albuterol), in accordance with ATS guidelines [19]. All subjects completed a standardized 6-minute walk test (6MWT) [20].

The presence of emphysema and gas trapping were determined in all subjects by computational analysis of chest CT scans using 3D SLICER software. Emphysema was measured as the percentage of lung with attenuation values less than or equal to $-950 \mathrm{HU}$ on inspiratory images, and gas trapping was measured as the percentage of lung less than or equal to $-856 \mathrm{HU}$ on expiratory images [21,22]. Airway wall thickness was measured using VIDA software (VIDA diagnostics, Iowa City, IA) by determining the square root wall area of a hypothetical airway of $10 \mathrm{~mm}$ internal perimeter (Pi10) [23].

\section{Statistical analysis}

The primary analysis included all subjects with GOLD stage 2 or higher COPD (post-bronchodilator $\mathrm{FEV}_{1} / \mathrm{FVC}$ $<0.7$ and $\mathrm{FEV}_{1}<80 \%$ predicted). Asthma was defined by subject report of a physician-diagnosis of asthma before the age of 40. Subjects with a diagnosis of asthma after the age of 40 or at an unknown age were excluded from this analysis. This age exclusion was chosen to improve the accuracy of the asthma diagnosis. Exacerbation frequency was dichotomized as zero COPD exacerbations compared with two or more COPD exacerbations in the year prior to study enrollment. All spirometry data were adjusted for age, race, gender, height, and pack-years of smoking [24].

Contingency tables and Fisher's exact test were performed for all univariate comparisons. Continuous variables were compared using nonparametric analysis with the Wilcoxon rank sum test. Linear and logistic regression models were performed to adjust for potentially confounding variables chosen based on known clinical confounders, in the following manner: BODE score, SGRQ, and COPD exacerbations were adjusted for age, gender, pack-years of smoking and race. Chest CT scan variables were adjusted for age, gender, race, BMI, smoking history, as well as type of CT scanner used. A logistic regression model was created to assess potential contributing factors to the diagnosis of asthma in subjects who have COPD.

\section{Results}

We examined the first 2500 subjects from the COPDGene study. Of these, 1059 subjects had COPD defined as GOLD stage 2-4. We excluded 144 subjects who did not provide information about their asthma history, leaving 915 subjects for analysis. Out of 915 COPD subjects, 119 (13\%) reported a physician's diagnosis of 
asthma prior to the age of 40. In comparison to subjects with COPD alone, subjects with COPD and asthma were younger (61.3 vs 64.7 years old, $\mathrm{p}=0.0001)$ and had fewer pack-years of smoking (43.7 vs 55.1, p < 0.0001) (Table 1). More subjects with COPD and asthma additionally reported a history of hay fever than subjects with COPD alone. There was no significant difference in gender among the groups or in current smoking status. There were more African-American COPD subjects who reported a history of asthma, and there were more subjects in this group who were frequent exacerbators in the year prior to enrollment (Figure 1).
In an unadjusted analysis, more subjects with COPD and asthma were currently taking inhaled corticosteroids in comparison to those with COPD alone $(\mathrm{p}<0.0001)$; however, when adjusted for $\mathrm{FEV}_{1}$, this difference was no longer significant (Table 1). A secondary analysis performed without the use of the age restriction in the definition of asthma demonstrated consistent findings. 1026 subjects were included and $223(21.7 \%)$ reported a history of asthma. In contrast to the restricted analysis, more women were found to additionally report a history of asthma (44\% with COPD only compared to $56 \%$ with COPD and asthma, $\mathrm{p}=0.012$ ).

Table 1 Characteristics of COPD cases (GOLD stage 2 or greater) with and without physician-diagnosed asthma.

\begin{tabular}{|c|c|c|c|}
\hline & COPD Only & COPD and Asthma & p-value \\
\hline Total Subjects & 796 & 119 & - \\
\hline \multicolumn{4}{|l|}{ Race: } \\
\hline Non-Hispanic white & $672(84.4)$ & $79(66.4)$ & $<0.0001$ \\
\hline African American & $124(15.6)$ & 40 (33.6) & \\
\hline \multicolumn{4}{|l|}{ Gender } \\
\hline Male & $423(53.1)$ & $61(51.3)$ & 0.77 \\
\hline Female & $373(46.9)$ & $58(48.7)$ & \\
\hline Age, years & $64.7(8.2)$ & $61.3(8.9)$ & $0.0001^{*}$ \\
\hline Pack-years of smoking & $55.1(27.3)$ & $43.7(20.7)$ & $<0.0001^{*}$ \\
\hline Current smoker & $270(34.2)$ & $46(38.7)$ & 0.35 \\
\hline $\mathrm{BMI} \mathrm{kg} / \mathrm{m}^{2}$ & $27.8(6.0)$ & $28.1(6.7)$ & $0.87^{*}$ \\
\hline \multicolumn{4}{|l|}{ GOLD Stage } \\
\hline 2 & $408(51.3)$ & $61(51.3)$ & $0.99^{* *}$ \\
\hline 3 & $251(31.5)$ & $38(31.9)$ & \\
\hline 4 & $137(17.2)$ & $20(16.8)$ & \\
\hline BODE Index & $3.0(2.1)$ & $3.2(1.9)$ & $0.28^{*}$ \\
\hline SGRQ & $38.6(20.5)$ & $44.0(21.9)$ & $0.0075^{*}$ \\
\hline 6MWT (ft) & $1140.2(431.9)$ & $1158.8(430.1)$ & $0.78^{*}$ \\
\hline Severe exacerbations & $140(17.6)$ & $39(32.8)$ & 0.0003 \\
\hline Frequent exacerbations & $114(18.0)$ & $41(42.7)$ & $<0.0001$ \\
\hline Hay fever & $204(27.8)$ & $65(57.0)$ & $<0.0001$ \\
\hline Inhaled corticosteroid use & $387(49.4)$ & $80(69.0)$ & $0.25^{* * *}$ \\
\hline $\mathrm{FEV}_{1} \%$ predicted & $49.4(18.4)$ & $49.2(17.5)$ & $0.85^{*}$ \\
\hline FVC \% predicted & $76.6(17.9)$ & $78.3(17.3)$ & $0.23^{*}$ \\
\hline $\mathrm{FEV}_{1} / \mathrm{FVC}$ & $0.48(0.13)$ & $0.48(0.12)$ & $0.62^{*}$ \\
\hline Presence of bronchodilator response, ATS definition & $270(36.0)$ & $46(41.1)$ & 0.30 \\
\hline Post bronchodilator \% change in $\mathrm{FEV}_{1}$ & $8.7(12.1)$ & $10.2(12.5)$ & $0.33^{*}$ \\
\hline Percent Emphysema, $-950 \mathrm{HU}$ & $15.8(13.5)$ & $13.7(12.3)$ & $0.18^{*}$ \\
\hline Percent gas-trapping, $-856 \mathrm{HU}$ & $42.1(20.3)$ & $43.1(20.5)$ & $0.69^{*}$ \\
\hline Airway wall thickness Pi10 & $3.78(0.12)$ & $3.80(0.14)$ & $0.34^{*}$ \\
\hline
\end{tabular}

Values are presented as mean (SD) or $\mathrm{N}(\%)$.

Abbreviations and definitions: $\mathrm{COPD}=$ chronic obstructive pulmonary disease; Hay fever = self report of a history of hay fever; BODE index $=$ body mass index airflow obstruction, dyspnea and exercise capacity index; SGRQ = St George's Respiratory Questionnaire; $6 \mathrm{MWT}=6$ minute walk test; Severe Exacerbations = presence of COPD exacerbation resulting in presentation to emergency room or hospital admission in year prior to presentation; Frequent exacerbations = two or more COPD exacerbations in the year prior to enrollment; FEV $1=$ forced expiratory volume in 1 second; FVC $=$ forced vital capacity; Bronchodilator response $=$ an increase in $\mathrm{FEV}_{1}$ of $>12 \%$ and $200 \mathrm{ml}$ after administrator of bronchodilator; Pi10 = square root wall area of a hypothetical airway of 10 mm internal perimeter. Data compared using Fisher's exact test unless otherwise stated. ${ }^{*}$ Wilcoxon rank sum analysis. ${ }^{* *} \mathrm{Chi}^{- \text {square }}$ analysis. ${ }^{* * *} \mathrm{p}$ value adjusted for FEV ${ }_{1}$. 


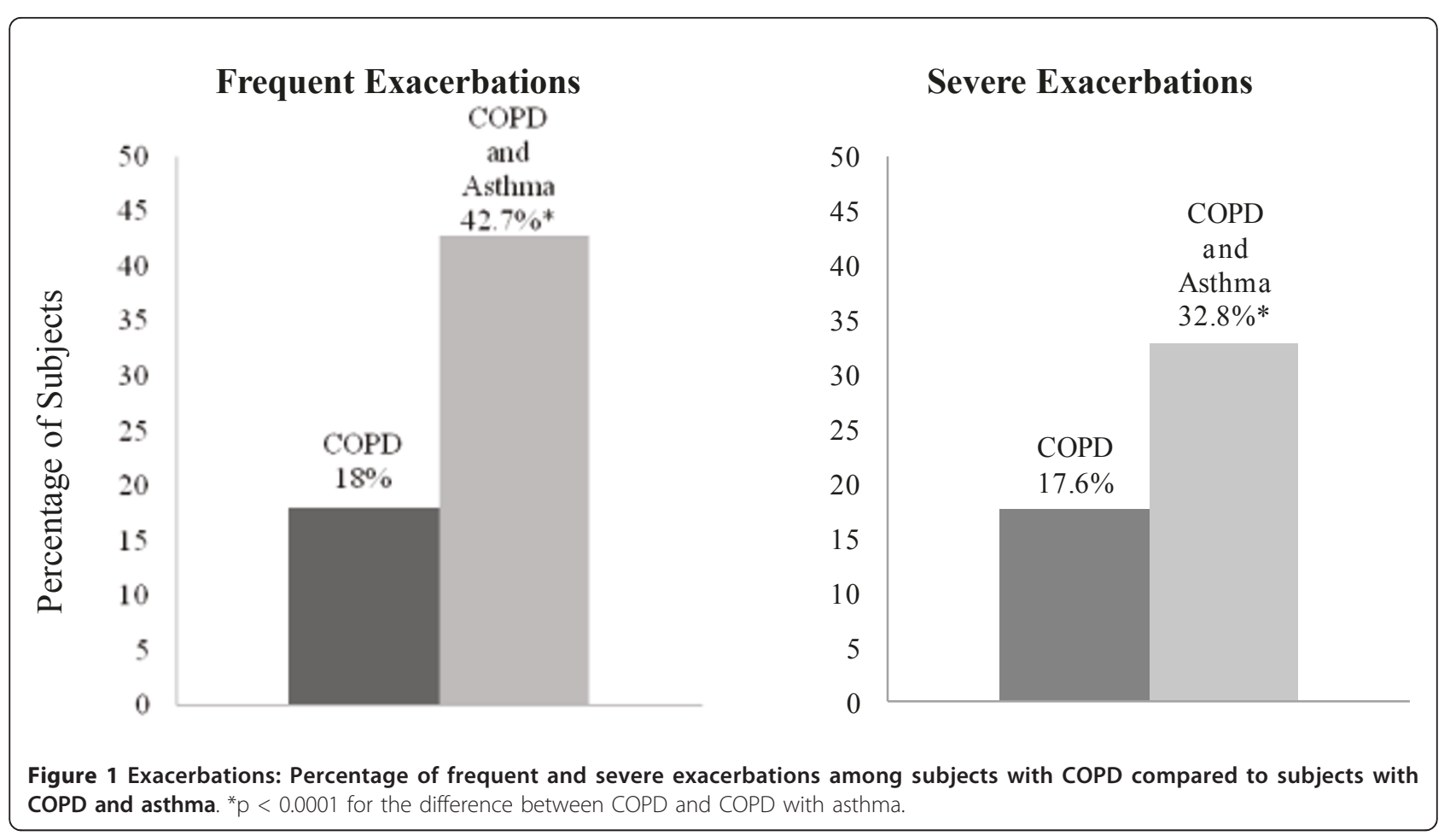

Table 2 shows that subjects with COPD and asthma demonstrated increased disease severity based on multiple measures. In multivariate comparisons adjusting for potential confounders including age, gender, pack-years of smoking and race, subjects with COPD and asthma had worse health-related quality of life, with a clinically significant 5.2 point higher SGRQ score $(\mathrm{p}=0.009)$. They were nearly twice as likely to experience severe respiratory exacerbations in the year prior to enrollment and were more than three times as likely to be frequent exacerbators in the year prior to enrollment. There was no significant difference in BODE index, 6MWT distance and spirometry, including $\mathrm{FEV}_{1}, \mathrm{FEV}_{1} / \mathrm{FVC}$ and bronchodilator response. Adjusting for BMI, age, gender, pack-years and race, subjects with COPD and asthma demonstrated greater gas trapping on expiratory CT scans as well as greater subsegmental wall area as measured by the parameter percent wall area $(66.2 \%$ vs $65.5 \%$ subsegmental wall area, $\mathrm{p}=0.013$ ) on inspiratory CT scans. There was no difference in percent

Table 2 Association of concurrent asthma diagnosis and COPD severity outcomes in COPD subjects.

\begin{tabular}{llll}
\hline Outcome & Additional Covariates & $\boldsymbol{\beta}(\mathrm{SE}) / \mathbf{O R}(\mathbf{C l})$ & $\mathbf{p}$-value \\
\hline BODE Index & age, gender, pack-years and race & $0.29(0.21)$ & 0.17 \\
\hline SGRQ & age, gender, pack-years and race & $5.2(2.0)$ & 0.009 \\
\hline 6MWT, ft & age, gender, pack-years and race & $31.6(40.5)$ & 0.43 \\
\hline Bronchodilator Response & age, gender, pack-years, and race & $1.40[0.92,2.13]$ & 0.12 \\
\hline Severe exacerbations & age, gender, pack-years and race & $1.93[1.24,3.02]$ & 0.004 \\
\hline Frequent exacerbations & age, gender, pack-years and race & $3.55[2.19,5.75]$ & $<0.0001$ \\
\hline Number of exacerbations & age, gender, pack-years and race & $0.68(0.12)$ & $<0.0001$ \\
\hline Percent Emphysema, -950HU & BMl, age, gender, pack-years, race and CT scanner* & $-0.45(1.23)$ & 0.71 \\
\hline Percent gas-trapping, -856HU & BMl, age, gender, pack-years, race and CT scanner & $4.31(1.88)$ & 0.02 \\
\hline Airway wall thickness Pi10 & BMl, age, gender, pack-years, race and CT scanner & $0.016(0.013)$ & 0.21 \\
\hline Abbra
\end{tabular}

Abbreviations and definitions: COPD = chronic obstructive pulmonary disease; BODE index = body mass index, airflow obstruction, dyspnea and exercise capacity index; SGRQ = St George's Respiratory Questionnaire; $6 \mathrm{MWT}=6$ minute walk test; Severe Exacerbations = presence of COPD exacerbation resulting in presentation to emergency room or hospital admission in year prior to presentation; Frequent exacerbations = two or more COPD exacerbations in the year prior to enrollment; Number of exacerbations = number of COPD exacerbations in the year prior to enrollment; Pi10 = square root wall area of a hypothetical airway of $10 \mathrm{~mm}$ internal perimeter. *Siemens 64 Sensation scanners gave aberrant lung density measurements and therefore this scanner type was adjusted as a covariate. 
emphysema or airway wall thickness (Pi10) on inspiratory chest CT scans.

In a logistic regression analysis examining predictors for the presence of asthma in subjects with COPD (Table 3), African-American race was associated with a two-fold increase in the risk of diagnosis of asthma. The diagnosis of asthma was less likely with increasing age or for every ten pack-years of smoking history.

In a stratified analysis in which the effect of asthma was examined separately among the subjects with moderate COPD (GOLD stage 2) and the subjects with severe and very severe COPD (GOLD stages 3 and 4), there was no significant difference in spirometry data based on asthma diagnosis. Among subjects with moderate COPD (GOLD stage 2), subjects with asthma and COPD overlap demonstrated greater percent gas-trapping on expiratory chest CT scans compared to those with COPD alone $(6.4+/-2.2 \%, \mathrm{p}=0.003)$. This difference was not seen among subjects with severe COPD $(-1.5+/-2.0 \%, \mathrm{p}=0.45)$. Among subjects with severe COPD there was a trend towards less percent emphysema on inspiratory CT scan in subjects with COPD and asthma compared to those with COPD alone (18.8\% vs $23.0 \%, p=0.05$ ). The presence of asthma was significantly associated with an increase in respiratory exacerbations regardless of COPD severity (among the moderate group: OR 3.60 [1.72, 7.54], $\mathrm{p}=0.007$; among the severe COPD group: OR $3.55[1.76,7.15], \mathrm{p}=$ $0.0004)$.

\section{Discussion}

In the COPDGene Study, we demonstrate that subjects with COPD and asthma have distinct and clinically-relevant characteristics. These subjects are more likely to be younger, African-American, and have less smoking history. However their lung function is similar to that of subjects with COPD alone. Despite this, they have worse health-related quality of life and are more likely to have frequent and severe respiratory exacerbations, a marker for more severe disease overall.

This is the first study to specifically link the presence of asthma to more frequent respiratory exacerbations in subjects with COPD. Recent studies have demonstrated that the presence of frequent exacerbations appears to be a stable phenotype of COPD that exists across all

Table 3 Multivariate logistic regression for predictors of asthma among subjects with COPD:

\begin{tabular}{lll}
\hline Variable & OR $[\mathrm{Cl}]$ & p-value \\
\hline African-American race & $2.05[1.31,3.21]$ & 0.002 \\
\hline Female gender & $0.94[0.63,1.40]$ & 0.76 \\
\hline Older age (per decade) & $0.76[0.60,0.97]$ & 0.03 \\
\hline Pack years of smoking (per 10 pack years) & $0.86[0.78,0.95]$ & 0.002 \\
\hline
\end{tabular}

levels of lung function and is identifiable by the presence of 2 or more exacerbations per year. In our study, the presence of frequent exacerbations was more common in subjects with COPD and asthma across all GOLD stages. Our findings are consistent with and extend the findings of a previous study demonstrating that patients with COPD and asthma have greater healthcare utilization related to pulmonary disease, with five times greater health care costs when compared to subjects with either disease alone [12]. These results have implications for disease management as the presence of increased COPD exacerbations has been associated with worse health-related quality of life as well as overall mortality $[25,26]$. The coexistence of asthma and COPD may identify a group of patients that are more likely to include frequent exacerbators and management of these patients should be directed towards exacerbation prevention.

This study is one of the first large studies to describe the chest CT scan findings in subjects with both COPD and asthma. These subjects demonstrated more gastrapping on expiratory chest CT scans compared to subjects with COPD alone. This is consistent with prior CT imaging studies demonstrating an increase in gas-trapping among subjects with asthma and may reflect an increase in small airway disease in this group [27]. There was no difference in emphysema or airway wall thickness between COPD subjects with and without asthma. When we restricted our analysis to subjects with moderate COPD, who may be expected to have the most variability in degree of emphysema, we did not see a difference in the percentage of emphysema between those subjects with COPD and those with COPD and asthma. Taken as a whole, these findings could suggest that airway inflammation rather than parenchymal destruction plays a greater role in the decrease in pulmonary function in subjects with COPD and asthma.

We additionally demonstrate a greater portion of subjects with asthma in the African-American population. These findings would suggest that clinicians should be more vigilant to screen for lung function decline in African-American patients with asthma, and similarly should be alert for an asthmatic component to African American subjects with COPD. This latter suggestion is supported by our multivariate analysis for clinical predictors of the diagnosis of asthma, in which we found that African-Americans with COPD were twice as likely to have asthma compared to white subjects with COPD. These findings could reflect a bias towards defining lung function decline in African American populations as asthma in comparison to COPD. These findings could also reflect the greater prevalence of asthma in this population [28]. Although prior studies have demonstrated that clinicians are less likely to diagnose COPD 
in women than in men [29], when examining subjects with a history of asthma diagnosed before age 40, we did not see a greater percentage of female subjects with asthma in addition to COPD. Of interest, when we examined our study population without the age restriction, we did see more women than men reporting a history of asthma.

Our study has several limitations. This is a cross-sectional study and therefore we are not able to address how COPD and asthma interact to produce this more severe disease phenotype. This would require a cohort analysis with decades of follow-up time, a potentially expensive and prolonged investigation. We were limited by our definition of asthma which included those subjects with a self report of a physician diagnosis of asthma. Self-report of physician diagnosis of asthma has been used previously in many large trials, and the percentage of subjects with asthma in COPDGene was similar to other large cohorts of subjects with COPD. More objective methods to diagnose asthma may be limited in subjects with COPD. Methacholine challenge testing in COPD subjects with FEV1 $<70 \%$ predicted has limited safety experience and can often be positive in the absence of asthma [30]. Based on self-report of physician diagnosis of asthma, we were able to identify a unique clinical phenotype among subjects with COPD. In addition, subjects with asthma demonstrated a greater incidence of atopy with more frequent occurrence of hay fever. The absence of a difference in bronchodilator responsiveness between subjects with and without asthma may reflect the overlapping nature of these diseases. Alternatively, one potential explanation is that subjects were not required to withhold their regular bronchodilator medication before spirometry testing. In order to further clarify the nature of respiratory disease between our two study populations, we examined pre-study respiratory medication use. Although in an unadjusted analysis we demonstrated that subjects with a history of asthma were more likely to be using inhaled corticosteroids, this difference did not remain significant when adjusted for $\mathrm{FEV}_{1}$. As inhaled corticosteroids are often used in the treatment of moderate to severe COPD as well as asthma, examining a history of this medication use may not be helpful in distinguishing subjects with asthma. We limited our inclusion to subjects diagnosed with asthma before the age of 40 in order to identify subjects whose asthma diagnosis preceded their COPD diagnosis and to exclude subjects who might have other respiratory diseases confused with asthma.

In conclusion, we demonstrate that subjects with COPD and asthma demonstrate unique clinical features including an increase in respiratory exacerbations. These findings have implications for disease management and treatment. Improved monitoring and prevention of exacerbations in patients with COPD and asthma may improve quality of life and potentially survival.

\section{Disclosures}

Dr. Silverman has received grant support and consulting fees from GlaxoSmithKline for studies of COPD genetics and has received honoraria and consulting fees from AstraZeneca. None of the other authors has reported conflicts of interest.

\section{Abbreviations}

6MWT: six-minute walk test; AHR: Airway hyperresponsiveness; ATS: American Thoracic Society; BMI: Body Mass Index; BODE: Body mass index, airflow Obstruction, Dyspnea, and Exercise capacity; Cl: Confidence Interval; COPD: Chronic Obstructive Pulmonary Disease; COPDGene: Genetic Epidemiology of COPD Study; HU: Hounsfield units; FEV $_{1}$ : forced expiratory volume in 1 second; FVC: forced vital capacity; GOLD: Global Initiative for Chronic Obstructive Lung Disease; OR: Odds Ratio; Pi10: square root wall area of a hypothetical airway of $10 \mathrm{~mm}$ internal perimeter; SGRQ: St. George's Respiratory Questionnaire.

\section{Acknowledgements}

This work was supported by the National Institutes of Health [T32 HL0742729(MH), U01HL089856 (E.K.S.), U01HL089897 (J.D.C.), K08HL080242 (C.P.H.), R01HL094635 (C.P.H.)]

The COPDGene $\left.{ }^{(}\right)$Investigators:

Ann Arbor VA: Jeffrey Curtis, MD (PI), Ella Kazerooni, MD (RAD)

Baylor College of Medicine, Houston, TX: Nicola Hanania, MD, MS (PI), Philip Alapat, MD, Venkata Bandi, MD, Kalpalatha Guntupalli, MD, Elizabeth Guy, MD, Antara Mallampalli, MD, Charles Trinh, MD (RAD), Mustafa Atik, MD Brigham and Women's Hospital, Boston, MA: Dawn DeMeo, MD, MPH (Co-PI), Craig Hersh, MD, MPH (Co-PI), George Washko, MD, Francine Jacobson, MD, MPH (RAD)

Columbia University, New York, NY: R. Graham Barr, MD, DrPH (PI), Byron

Thomashow, MD, John Austin, MD (RAD)

Duke University Medical Center, Durham, NC: Neil Maclntyre, Jr., MD (PI), Lacey Washington, MD (RAD), H Page McAdams, MD (RAD)

Fallon Clinic, Worcester, MA: Richard Rosiello, MD (PI), Timothy Bresnahan, MD (RAD)

Health Partners Research Foundation, Minneapolis, MN: Charlene McEvoy, MD, MPH (PI), Joseph Tashjian, MD (RAD)

Johns Hopkins University, Baltimore, MD: Robert Wise, MD (PI), Nadia Hansel, $M D, M P H$, Robert Brown, MD (RAD), Gregory Diette, MD

Los Angeles Biomedical Research Institute at Harbor UCLA Medical Center, LOS Angeles, CA: Richard Casaburi, MD (PI), Janos Porszasz, MD, PhD, Hans Fischer, $\mathrm{MD}, \mathrm{PhD}(\mathrm{RAD})$, Matt Budoff, MD

Michael E. DeBakey VAMC, Houston, TX: Amir Sharafkhaneh, MD (PI), Charles Trinh, MD (RAD), Hirani Kamal, MD, Roham Darvishi, MD

Minneapolis VA: Dennis Niewoehner, MD (PI), Tadashi Allen, MD (RAD), Quentin Anderson, MD (RAD), Kathryn Rice, MD

Morehouse School of Medicine, Atlanta, GA: Marilyn Foreman, MD, MS (PI), Gloria Westney, MD, MS, Eugene Berkowitz, MD, PhD (RAD)

National Jewish Health, Denver, CO: Russell Bowler, MD, PhD (PI), Adam Friedlander, MD, David Lynch, MB (RAD), Joyce Schroeder, MD (RAD), John Newell, Jr., MD (RAD)

Temple University, Philadelphia, PA: Gerard Criner, MD (PI), Victor Kim, MD, Nathaniel Marchetti, DO, Aditi Satti, MD, A. James Mamary, MD, Robert Steiner, MD (RAD), Chandra Dass, MD (RAD)

University of Alabama, Birmingham, AL: William Bailey, MD (PI), Mark Dransfield, MD (Co-PI), Hrudaya Nath, MD (RAD)

University of California, San Diego, CA: Joe Ramsdell, MD (PI), Paul Friedman, $\mathrm{MD}$ (RAD)

University of lowa, lowa City, IA: Geoffrey McLennan, MD, PhD (PI), Edwin JR van Beek, MD, PhD (RAD), Brad Thompson, MD (RAD), Dwight Look, MD University of Michigan, Ann Arbor, MI: Fernando Martinez, MD (PI), MeiLan Han, MD, Ella Kazerooni, MD (RAD) 
University of Minnesota, Minneapolis, MN: Christine Wendt, MD (PI), Tadashi Allen, MD (RAD)

University of Pittsburgh, Pittsburgh, PA: Frank Sciurba, MD (PI), Joel Weissfeld, MD, MPH, Carl Fuhrman, MD (RAD), Jessica Bon, MD

University of Texas Health Science Center at San Antonio, San Antonio, TX: Antonio Anzueto, MD (PI), Sandra Adams, MD, Carlos Orozco, MD, Mario Ruiz, MD (RAD)

Administrative Core: James Crapo, MD (PI), Edwin Silverman, MD, PhD (PI), Barry Make, MD, Elizabeth Regan, MD, Jonathan Samet, MD, Sarah Moyle, MS, Douglas Stinson

Genetic Analysis Core: Terri Beaty, PhD, Barbara Klanderman, PhD, Nan Laird, PhD, Christophe Lange, PhD, Michael Cho, MD, Stephanie Santorico, PhD, John Hokanson, MPH, PhD, Dawn DeMeo, MD, MPH, Nadia Hansel, MD, MPH, Jacqueline Hetmanski, MS, Tanda Murray

Imaging Core: David Lynch, MB, Joyce Schroeder, MD, John Newell, Jr., MD, John Reilly, MD, Harvey Coxson, PhD, Philip Judy, PhD, Eric Hoffman, PhD, Raul San Jose Estepar, PhD, James Ross, MSc, Rebecca Leek, Jordan Zach, Alex Kluiber, Jered Sieren, Heather Baumhauer, Verity McArthur, Dzimitry Kazlouski, Andrew Allen, Tanya Mann

PFT QA Core, LDS Hospital, Salt Lake City, UT: Robert Jensen, PhD Biological Repository, Johns Hopkins University, Baltimore, MD: Homayoon Farzadegan, PhD, Stacey Meyerer, Shivam Chandan, Samantha Bragan Data Coordinating Center and Biostatistics, National Jewish Health, Denver, CO: James Murphy, PhD, Douglas Everett, PhD, Ruthie Knowles, Amber Powell, Carla Wilson

Epidemiology Core, University of Colorado School of Public Health, Denver, CO: John Hokanson, MPH, PhD, Jennifer Black-Shinn, MPH, Gregory Kinney, MPH

\section{Author details}

${ }^{1}$ Channing Laboratory, Brigham and Women's Hospital, Harvard Medical School, Boston, MA, USA. Division of Pulmonary and Critical Care Medicine, Brigham and Women's Hospital, Harvard Medical School, Boston, MA, USA. ${ }^{3}$ Department of Medicine, College of Physicians and Surgeons, Columbia University, New York, NY, USA. ${ }^{4}$ Department of Pulmonary and Critical Care Medicine, Johns Hopkins University, Baltimore, MD, USA. ${ }^{5}$ Division of Pulmonary Sciences and Critical Care Medicine, National Jewish Health, Denver, CO, USA.

\section{Authors' contributions}

Study conception and design: $\mathrm{MH}, \mathrm{CH}$. Data collection: $\mathrm{MH}, \mathrm{ES}, \mathrm{RB}, \mathrm{NH}, \mathrm{JS}$, $\mathrm{BM}, \mathrm{JC}, \mathrm{CH}$. Data analyses and statistical support: $\mathrm{CH}, \mathrm{MH}$. Manuscript writing and editing: $\mathrm{MH}, \mathrm{ES}, \mathrm{RB}, \mathrm{NH}, \mathrm{BM}, \mathrm{JC}, \mathrm{CH}$. MH takes full responsibility for the work represented in this manuscript.

All authors have read and approved the final manuscript.

\section{Competing interests}

The authors declare that they have no competing interests.

Received: 26 May 2011 Accepted: 27 September 2011

Published: 27 September 2011

\section{References}

1. Minino AM, Xu J, Kochanek KD: Deaths: Preliminary data for 2008. National Vital Statistics Reports 2010, 59(2):1-71.

2. Mannino DM, Homa DM, Akinbami LJ, Ford ES, Ress SC: Chronic obstructive pulmonary disease surveillance - United States, 1971-2000. MMWR Surveill Summ 2002, 51:1-16.

3. Jemel A, Ward E, Hao Y, Thun M: Trends in the leading causes of death in the United States, 1970-2002. JAMA 2005, 294:1255-1259.

4. From the Global Strategy for the Diagnosis, Management and Prevention of COPD 2010 [http://www.goldcopd.org], Global Initiative for Chronic Obstructive Lung Disease (GOLD).

5. Hersh CP, Jacobsen FL, Gill R, Silverman EK: Computed tomography phenotypes in severe, early-onset chronic obstructive pulmonary disease. COPD 2007, 4:331-337.

6. Soriano JB, Davis KJ, Coleman B, Visick G, Mannino D, Pride NB: The proportional venn diagram of obstructive lung disease: two approximations from the United States and the United Kingdom. Chest 2003, 124:474-481.
7. Rijcken B, Schouten JP, XU X, Rosner B, Weiss ST: Airway hyperresponsiveness to histamine associated with accelerated decline in FEV1. Am J Respir Crit Care Med 1995, 151(5):1377-1382.

8. Tashkin DP, Altose MD, COnnett JE, Kanner RE, Lee WW, Wise RA: Methacholine reactivity predicts changes in lung function over time in smokers with early chronic obstructive pulmonary disease. The lung health study research group. Am J Respir Crit Care Med 1996, 153(6Pt1):1802-1811.

9. Lange P, Parner J, Vestbo J, Schnohr P, Jensen G: A 15-Year follow-up study of ventilatory function in adults with asthma. N Engl J Med 1998, 339(17):1194-1200.

10. Silva GE, Sherrill DL, Guerra S, Barbee RA: Asthma as a risk factor for COPD in a longitudinal study. Chest 2004, 126(1):59-65.

11. Hospers JJ, Postma DS, Jijcken B, Weiss ST, Schouten JP: Histamine airway hyper-responsiveness and mortality from chronic obstructive pulmonary disease: a cohort study. Lancet 2000, 356(9238):1313-1317.

12. Soriano JB, Visick GT, Muellerova H, Payvandi N, Hansell AL: Patterns of comorbidities in newly diagnosed COPD and asthma in primary care. Chest 2005, 128(4):2099-2107.

13. Shaya FT, Dongyi D, Akazawa MO, Blanchette CM, Wang J, Mapel DW, Dalal A, Scharf SM: Burden of concomitant Asthma and COPD in a medicaid population. Chest 2008, 134:14-19.

14. Kraft M: Asthma and chronic obstructive pulmonary disease exhibit common origins in any country! Am J Respir Crit Care Med 2006, 174(3):238-244.

15. Regan EA, Hokanson JE, Murphy JR, Make B, Lynch DA, Beaty TH, CurranEverett D, Silverman EK, Crapo JD, the COPDGene Investigators: Genetic epidemiology of COPD (COPDGene) study design. COPD 2010, 7(1):32-43.

16. Jones PW, Quirk FH, Baveystock CM, Littlejohns P: A self-complete measure of health status for chronic airflow limitation. The St. George's Respiratory Questionnaire. Am Rev Respir Dis 1992, 145(6):1321-1327.

17. Celli BR, Cote CG, Marin JM, Casanova C, Montes de Oca M, Mendez RA, Pinto Plata V, Cabral HJ: The body-mass index, airflow obstruction, dyspnea, and exercise Capacity Index in Chronic Obstructive Pulmonary Disease. N Engl J Med 2004, 350:1005-1012.

18. Hurst JR, Vestbo J, Anzueto A: Susceptibility to exacerbation in chronic obstructive pulmonary disease. N Engl J Med 2010, 363(12):1128-1138.

19. American Thoracic Society: Standardization of spirometry, 1994 Update. Am J Respir Crit Care Med 1995, 152(3):1107-1136.

20. ATS Committee on Proficiency Standards for Clinical Pulmonary Funciton Laboratories: ATS statement: guidelines for the six-minute walk test. Am J Respir Crit Care Med 2002, 166:111-117.

21. Nakano Y, Muller NL, King GG, Niimi A, Kalloger SE, Mishima M, Pare PD: Quantitative assessment of airway remodeling using high-resolution $C T$. Chest 2002, 122:271S-275S.

22. Hasegawa M, Nasuhara Y, Onodera Y, Makita H, Nagai K, Fuke S, Ito Y, Betsuyaku T, Nishimura M: Airflow limitation and airway dimensions in chronic obstructive pulmonary disease. Am J Respir Crit Care Med 2006, 173(12):1309-1315.

23. Hoffman EA, Gnanaprakasam D, Gupta KB, Hoford JD, Kugelmass SD, Kulawiec RS: VIDA: An Environment for multidimensional image display and analysis. SPIE Proc 1992, 1660:694-711.

24. Hankinson JL, Odencrantz JR, Fedan KB: Spirometric reference values from a sample of the general U.S. population. Am J Respir Crit Care Med 1999, 159(1):179-187.

25. Seemungal TA, Donaldson GC, Paul EA, Bestall JC, Jeffries DJ, Wedzicha JA: Effect of Exacerbation on Quality of Life in Patients with Chronic Obstructive Pulmonary Disease. Am J Respir Crit Care Med 1998, 157(5pt1):1418-1422.

26. Soler-Cataluna JJ, Martinez-Garcia MA, Roman Sanchez P, Salcedo E, Navarro M, Ochando R: Severe Acute Exacerbations and Mortality in Patients with Chronic Obstructive Pulmonary Disease. Thorax 2005, 60(11):925-931.

27. Gono H, Fujimoto K, Kawakami S, Kubo K: Evaluation of Airway Wall Thickness and Air Trapping by HRCT in Asymptomatic Asthma. Eur Respir J 2003, 22(6):965-971.

28. Moorman JE, Zahran H, Truman BI, Molla MT: "MMWR; Current Asthma Prevalence: United States". MMWR 2011, 60(01):84-86.

29. Chapman KR, Tashkin DP, Pye DJ: Gender Bias in the Diagnosis of COPD. Chest 2001, 119:1691-1695. 
30. Busse WW, Wanner A, Adams K, Reynolds HY, Castro M, Chowdhury B, Kraft M, Levine RJ, Peters SP, Sullivan EJ: Investigative Bronchoprovocation and Bronchoscopy in Airway Diseases. Am J Respir Crit Care Med 2005, 172:807-816

doi:10.1186/1465-9921-12-127

Cite this article as: Hardin et al:: The clinical features of the overlap between COPD and asthma. Respiratory Research 2011 12:127.

Submit your next manuscript to BioMed Central and take full advantage of:

- Convenient online submission

- Thorough peer review

- No space constraints or color figure charges

- Immediate publication on acceptance

- Inclusion in PubMed, CAS, Scopus and Google Scholar

- Research which is freely available for redistribution

Submit your manuscript at www.biomedcentral.com/submit 